\title{
Educação a distância como recurso para capacitação de Agentes Comunitários de Saúde para intervenções preventivas relacionadas ao álcool e outras drogas
}

\author{
Long-distance learning as a resource for capacity of Community Health \\ Agents on preventive interventions related to alcohol and other drugs
}

\section{Educación a distancia como recurso para la capacitación de Agentes Comunitarios de Salud sobre intervenciones preventivas relacionadas con el alcohol y otras drogas}

\author{
Maíra Gussi de Oliveira ${ }^{1, a}$ \\ maira.gussi@gmail.com | http://orcid.org/o000-0003-3993-1809
}

Cibele Maria de Sousa ${ }^{1, \mathrm{~b}}$

cimaria1@yahoo.com.br | https://orcid.org/0000-0003-0302-9047

Cláudia Regina Merçon de Vargas ${ }^{1, c}$

cvmercon@gmail.com | https://orcid.org/o0oo-0003-2732-9618

Donizete Moreira de Oliveira ${ }^{1, \mathrm{~d}}$

donizetem@gmail.com | https://orcid.org/o0oo-0002-6949-4921

Maria da Glória Lima ${ }^{1, \mathrm{e}}$

limamg@unb.br | https://orcid.org/o000-0001-6450-9154

Maria Aparecida Gussi i.f

gussi@unb.br | https://orcid.org/o0oo-0002-3069-5312

${ }^{1}$ Universidade de Brasília, Brasília, DF, Brasil.

a Graduação em Serviço Social pela Universidade de Brasília.

b Especialização em Violência Doméstica Contra Crianças e Adolescentes pela Universidade de São Paulo.

c Mestrado em Ciências da Saúde pela Universidade de Brasília.

d Especialização em Educação a Distância: Elaboração de Material, Tutoria e Ambientes V. pela Universidade Cruzeiro do Sul.

e Doutorado em Enfermagem pela Universidade de São Paulo.

f Doutorado em Ciências da Saúde pela Universidade de Brasília.

\section{Resumo}

Agentes Comunitários de Saúde são estratégicos no trabalho da Atenção Básica, por conviverem mais diretamente com as questões de saúde no território, e o enfrentamento dos problemas relacionados ao uso de álcool e outras drogas requer investimento na qualificação desses profissionais. O artigo relata a experiência do Curso de Capacitação de Agentes Comunitários de Saúde para ações preventivas ao uso de álcool e outras drogas, realizado na modalidade de educação a distância, com formato autoinstrucional e acompanhamento tutorial. $\mathrm{O}$ uso de ferramentas tecnológicas, além da articulação com a rede de serviços e acompanhamento tutorial, se mostrou um potente recurso para desenvolvimento de educação permanente em serviço. A tutoria foi um diferencial na maior adesão e interesse no curso, ao permitir a aquisição de conceitos e estratégias de saúde para melhor atender as necessidades dos usuários, segundo as prerrogativas do Sistema Único de Saúde e do modelo de atenção psicossocial.

Palavras-chave: Agentes comunitários de saúde; Educação a distância; Tutoria; Saúde mental; Saúde da família; Transtornos relacionados ao uso de substâncias. 


\begin{abstract}
The Community Health Workers are one of the strategic agents in the work of Primary Care, because they live more directly with health issues in the territory, considering that the problems related to the use of alcohol and other drugs require investment focused on the qualification of health professional. Therefore, this article aimed to report the experience of the Capacity Course of Community Health Agents towards preventive actions from alcohol and other drugs, conducted in the modality of self-instructional distance learning, with tutorial accompaniment. The use of technological tools, besides the articulation with the service network and tutorial accompaniment, proved to be a powerful resource for the development of permanent education in service, in which tutoring was a differential in the enrollment and interest of these professionals in the course, in a way that allows the acquisition of concepts and health strategies to better answer the users needs, according to the prerogatives of the Unified Health System and the psychosocial care model.
\end{abstract}

Keywords: Community health workers; Education, distance; Mentoring; Mental health; Family health; Substance-related disorders.

\title{
Resumen
}

Los Agentes Comunitarios de Salud son uno de los agentes estratégicos en el trabajo de la Atención Básica, por convivir más directamente con las cuestiones de salud en el territorio, siendo que el confrontamiento de los problemas relacionados al uso del alcohol y otras drogas requiere invertir en la calificación de los profesionales de la salud. Así, el objetivo de este artículo fue relatar la experiencia del Curso de Capacitación de Agentes Comunitarios de Salud para acciones de prevención al uso de alcohol y otras drogas, realizado mediante educación a distancia, de formato autoinstruccional y con acompañamiento tutorial. El uso de herramientas tecnológicas, además de la articulación con la red de servicios y el acompañamiento tutorial, se mostró un potente recurso para el desarrollo de la educación permanente en servicio, en el cual la tutoría fue un diferencial en la adhesión e interés de estos profesionales en el curso, de manera que permitió la adquisición de conceptos y estrategias de salud para mejorar la atención de las necesidades de los usuarios, según las prerrogativas del Sistema Único de Salud y del modelo de atención psicosocial.

Palabras clave: Agentes comunitarios de salud; Educación a distancia; Tutoría; Salud mental; Salud de la familia; Trastornos relacionados con sustancias.

INFORMAÇÕES DO ARTIGO

\begin{abstract}
Contribuição dos autores:
Todos os autores se envolveram igualmente nas etapas de construção do trabalho: Concepção e desenho do estudo; Aquisição, análise ou interpretação dos dados; Redação do manuscrito; Revisão crítica do conteúdo intelectual.
\end{abstract}

Declaração de conflito de interesses: não há.

Fontes de financiamento: ministério da Saúde.

Considerações éticas: aprovado pelos Comitês de Ética da Faculdade de Ciências da Saúde da Universidade de Brasília (CEP/FSUnB), sob parecer de n. 2.200.022 e, também da Fundação de Ensino e Pesquisa em Ciências da Saúde - FEPECS/SES/DF, parecer de n. 2.270.086, como uma das ações do projeto 'Reorganização dos e nos processos de trabalho na Rede de Atenção Psicossocial mediada pela avaliação participativa'.

Agradecimentos/Contribuições adicionais: não há.

Histórico do artigo: submetido: 05 set. 2018 | aceito: 28 fev. 2019 | publicado: 29 mar. 2019

Apresentação anterior: não houve.

Licença CC BY-NC atribuição não comercial. Com essa licença é permitido acessar, baixar (download), copiar, imprimir, compartilhar, reutilizar e distribuir os artigos, desde que para uso não comercial e com a citação da fonte, conferindo os devidos créditos de autoria e menção à Reciis. Nesses casos, nenhuma permissão é necessária por parte dos autores ou dos editores. 


\section{Introdução}

A formação de recursos humanos em saúde passou a ser ordenada pelo Sistema Único de Saúde (SUS) a partir de sua aprovação com a Constituição Federal de 1988. Garantir a qualificação dos profissionais na perspectiva do cuidado integral, de modo a aprimorar cada vez mais a prática, é um desafio que implica repensar constantemente o modo de ensinar e aprender.

A educação permanente em saúde está relacionada à necessidade de os trabalhadores da saúde refletirem sobre sua prática, bem como de uma atualização técnico-científica e do estreitamento dos diálogos com os usuários e demais profissionais. Essa educação está inserida num contexto de tensionamento em que, ao passo em que há a possibilidade de uma mera reprodução do trabalho técnico, é possível também formular novos processos de trabalho de modo que os trabalhadores respondam de forma mais pertinente às necessidades de saúde dos usuários e busquem assegurar direitos e qualidade na prestação do serviço1.

Desse modo, é possível depreender que o potencial da educação permanente em saúde relaciona-se às reflexões e ressignificação das práticas e, ainda, à construção de novas formas de fazer saúde dentro de uma lógica de transformação do cotidiano profissional na perspectiva de fortalecimento do SUS.

No âmbito dessa reflexão sobre educação permanente em saúde, destaca-se neste relato de experiência o papel da Educação a Distância (EAD) que, no Brasil, é recente e tem alcançado impulso e expressão na Lei de Diretrizes e Bases da Educação Nacional (LDB), n. 9394 de 20/12/1996², que a insere como modalidade regular que integra o sistema educacional nacional. Tal forma de ensino é facilitadora da autoaprendizagem, com auxílio de recursos didáticos organizados, apresentados em diversos suportes de informação cuja utilização se dá nos mais diferentes meios de comunicação .

Entretanto, cabe dizer que nem sempre a EAD foi bem vista. Durante muito tempo ela foi considerada uma espécie de educação de baixa qualidade, pois surgiu como forma de atender às pessoas que não conseguiam ser incluídas na educação formal e passou a ser encarada como se fosse de baixa exigência. Antes dos avanços tecnológicos, os meios de comunicação mais comuns usados pela EAD eram cartas, telefones, rádio e a televisão; e um dos grandes problemas desse tipo de educação no passado era a falta de interatividade entre as pessoas que participavam dos processos de formação, entre os estudantes e professores, o que contribuía para desestimular as pessoas envolvidas ${ }^{4}$.

Porém, com a mudança no cenário tecnológico e a crescente ampliação do uso de Tecnologias de Informação e Comunicação (TICs), que contribuem efetivamente para que o mundo virtual se faça presente em realidades específicas, de cada grupo social ${ }^{5}$, pode-se dizer que a interatividade vem sendo expandida e a possibilidade de interagir simultaneamente com um número maior de pessoas aumenta a cada dia.

A EAD, nesse contexto em que o processo de aquisição de conhecimento adquire maior velocidade e sugere novas formas de aprendizagem, diminui distâncias, pode atender um número maior de pessoas. Ademais, a informação por meio da EAD favorece a flexibilização de tempo, espaço e conteúdo.

A assistência à saúde pelo SUS, de acordo com o texto constitucional de 1988, complementado e aperfeiçoado pela Lei Orgânica da Saúde, deve abranger tanto as ações assistenciais ou curativas quanto,

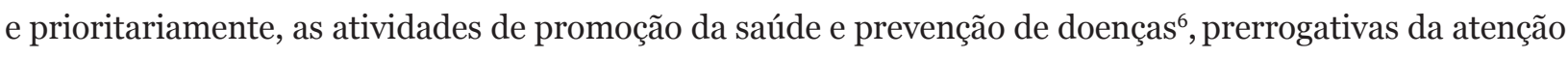
primária. Assim, a expansão e a qualificação da atenção básica, organizadas pela Estratégia Saúde da Família (ESF), compõem parte do conjunto de prioridades políticas apresentadas pelo governo brasileiro, por meio do Ministério da Saúde e aprovadas pelo Conselho Nacional de Saúde.

A ESF, desde 1994, momento da sua criação, incorpora a responsabilidade de mudar o modelo de atenção à saúde no Brasil, reestruturando a atenção básica no conjunto dos sistemas municipais de saúde. Dessa forma, a rede de serviços em seus diferentes níveis é viabilizada para assegurar assistência integral aos indivíduos, famílias e comunidades, e para melhorar o padrão sanitário da população, priorizando os grupos em desvantagem social. 
Em 1991 o Ministério da Saúde oficializou o Programa de Agentes Comunitários de Saúde (Pacs). Sua criação teve por objetivo central estender as ações básicas de saúde aos núcleos familiares, no próprio domicílio, com uma agenda de trabalho prioritário direcionada ao grupo materno infantil. Os Agentes Comunitários de Saúde (ACS) ocupam uma posição de destaque dentre os profissionais que integram a equipe da ESF, pois convivem mais diretamente com os problemas de saúde no território de atuação, conhecem as pessoas assistidas, têm linguagem semelhante a elas, moram no mesmo território, o que pode contribuir para que uma informação fornecida pelo referido profissional tenha grande credibilidade ${ }^{7}$. Lidando com as pessoas em situação de sofrimento mental relacionados ao uso de álcool e outras drogas e seus familiares, a intervenção dos ACS possibilita o desenvolvimento de ações preventivas e de educação em saúde, em consonância com o modelo de atenção psicossocial.

No ano de 2011 foi instituída a Rede de Atenção Psicossocial (Raps) que tem como objetivo criar, ampliar e articular pontos de atenção à saúde para pessoas com sofrimento ou transtorno mental e com necessidades decorrentes do uso de álcool e outras drogas, no âmbito do SUS8. A Atenção Básica em Saúde é um dos componentes da Raps juntamente com os Centros de Atenção Psicossocial (Caps), Serviço de Atendimento Móvel de Urgência (Samu), Rede Hospitalar, dentre outros. Na lógica de um trabalho em rede, o potencial articulador e mobilizador do ACS é fundamental para socializar com a população o funcionamento da rede supracitada, bem como, para articular seus pontos de atenção e desenvolver ações conjuntas.

Ressalta-se ainda que o uso de drogas é considerado um fenômeno complexo, problema social e de saúde pública, não só pelo que apontam as estatísticas, mas por todo impacto causado na vida individual e coletiva9 ${ }^{9}$. Ademais, as características do trabalho do ACS podem ser potencializadas por meio da adequada utilização da Informação, Educação e Comunicação em Saúde (IEC). Portanto, pensar na perspectiva da inclusão digital dos ACS pode corroborar para aperfeiçoar o processo de conhecimento a distância com rebatimentos positivos às famílias e comunidades assistidas por eles no que se refere à construção e ao acesso a uma rede de informação, de educação e comunicação acerca das questões de saúde pública ${ }^{10}$.

Nessa perspectiva, o objetivo deste trabalho é descrever a experiência da pesquisa intervenção do Curso de Capacitação para ACS, na modalidade EAD autoinstrucional, para ações preventivas em situações de uso, abuso e dependência de substâncias psicoativas no território.

\section{Metodologia}

Este estudo qualitativo de intervenção prática abarca o desenvolvimento do 'Curso de Capacitação de Agentes Comunitários de Saúde para ações preventivas ao uso de álcool e outras drogas', realizado pelo Observatório de Políticas de Atenção à Saúde Mental no Distrito Federal (Obsam), pertencente ao Núcleo de Estudos em Saúde Pública (Nesp), da Universidade de Brasília (UnB).

O curso teve duração de nove semanas, entre julho e agosto de 2017, com carga horária de 80 horas/ aula. Utilizou-se como ambiente virtual de aprendizagem (AVA) o software livre Modular Object - Oriented Dynamic Learning Environment - Moodle, com suporte de tutoria e oferta de atividades de aprendizagem, por meio de oito aulas com leitura de texto orientador, exercícios avaliativos, biblioteca para aprofundamento do conhecimento e fóruns de notícias e de orientações e dúvidas.

A implementação do curso envolveu as seguintes etapas: 1- Planejamento (levantamento de necessidades, elaboração de conteúdo, elaboração do protótipo e implantação na plataforma moodle); 2- Desenvolvimento e implantação do curso (capacitação da tutoria, formação da turma, e realização das atividades previstas); e 3- Avaliação do curso por meio de questionário eletrônico e grupo focal avaliativo com os ACS.

A etapa de levantamento de necessidades de formação dos ACS, realizada em 2013, foi estruturante para a elaboração da proposta pedagógica e seleção dos conteúdos contemplados. Foi realizado um levantamento das percepções e demandas dos ACS sobre as questões relacionadas ao uso de álcool e outras drogas no âmbito 
da atenção básica, por meio da pesquisa intitulada 'Formação dos Agentes Comunitários de Saúde nas ações preventivas ao uso indevido de drogas mediado por tecnologias da informação, educação e comunicação'.

O processo de elaboração do material didático envolveu uma equipe de profissionais qualificados na área e articulados com a Raps. Contou com uma análise das demandas levantadas pelos ACS, além uma revisão da literatura especializada do assunto e discussão em equipe dos aspectos a serem contemplados nas aulas e dos recursos pedagógicos a serem adotados, de modo a ampliar e favorecer o preparo profissional para atuar no trabalho coletivo junto aos usuários, familiares e comunidades. Todo o material foi adaptado ao AVA e novamente discutido em equipe.

Com o material do curso elaborado, iniciou-se o processo de divulgação e mobilização dos cursistas. A inscrição dos participantes ocorreu por meio da pactuação com os Centros de Atenção Psicossocial Álcool e Drogas (Caps-AD) do Distrito Federal (DF) para que articulassem, junto às equipes da ESF do seu território de abrangência, a indicação dos ACS. Essa estratégia visou favorecer a articulação dos Caps para o fortalecimento da rede de saúde e ações de matriciamento.

Quatro dos sete Caps-AD foram contatados por já participarem de outras atividades do Obsam e aceitaram fazer essa parceria para o projeto piloto, são eles: Caps-AD Ceilândia, Caps-AD Samambaia, Caps-AD Santa Maria e Caps-AD Sobradinho. Foram ofertadas 50 vagas, e os 45 inscritos foram distribuídos em duas turmas.

Ao longo do curso, os ACS tiveram o suporte de tutoria para o esclarecimento de dúvidas, incentivo a uma participação colaborativa, à troca de experiências e à construção do conhecimento para a intervenção profissional quanto ao uso de álcool e outras drogas no âmbito da ESF.

A preparação da equipe de tutoria envolveu a capacitação permanente das tutoras quanto aos aspectos teóricos e manejo da plataforma, com discussão do conteúdo e das estratégias de mobilização adotadas. Todo este processo foi supervisionado e orientado por duas especialistas de conteúdo e por um profissional para suporte técnico do AVA, além de reuniões presenciais com a coordenação do curso para avaliar o processo durante o percurso de realização e alinhar as abordagens educacionais implementadas.

A avaliação da aprendizagem ocorreu por meio de exercícios avaliativos objetivos realizados ao final das aulas 2 a 7, com oportunidade de até dois envios para correção, prevalecendo a maior nota. Os cursistas aprovados receberam certificado emitido pelo Decanato de Extensão da UnB.

Para avaliar o curso, foi disponibilizado, por dez dias, um questionário no Moodle, com perguntas objetivas e subjetivas, respondido anonimamente por 36 dos 44 concluintes, de 45 ACS inscritos. O questionário contemplou questões fechadas e abertas sobre os seguintes tópicos: conteúdo, exercício, plataforma, atuação das tutoras, biblioteca, autoavaliação e aspectos gerais do curso.

Após a conclusão do curso, foram realizados dois Grupos Focais, com uso de roteiro semiestruturado, com uma amostra intencional de conveniência, mediante convite a todos os ACS que concluíram o curso, considerando a sua vinculação profissional nas Regionais de Saúde de Samambaia e de Sobradinho. Assim, 17 ACS compareceram aos grupos, sendo 11 no de Samambaia, com duração de 2 ho5 minutos, e seis ACS no de Sobradinho, de $1 \mathrm{~h} 15 \mathrm{~min}$, realizados em setembro e novembro de 2017, respectivamente. Todos os participantes expressaram a sua concordância mediante a assinatura do Termo de Consentimento Livre e Esclarecido.

Essatécnicafoi escolhida porproporcionarum espaçoprivilegiadodediscussãoetrocas deexperiência sobre um tema específico, permitindo o debate entre os participantes, como também, um maior aprofundamento da reflexão, além da compreensão de percepções, crenças e opiniões ${ }^{11}$. Os grupos focais contaram com a participação de três pesquisadoras do projeto que participaram da concepção e desenvolvimento do curso, uma especialista no tema álcool e outras drogas e duas que participaram ainda na qualidade de tutoras do curso, momento em que os ACS tiverem a oportunidade de conhecê-las pessoalmente. As três pesquisadoras se distribuíram nas seguintes funções: uma mediadora, outra observadora, com registro em um diário de campo, e a intervenção da especialista temática, mais ao final do grupo. 
Na ocasião, foram compartilhados os resultados da avaliação sobre a experiência do curso e aprofundadas algumas questões sobre as concepções apresentadas acerca do usuário de álcool e outras drogas, as mudanças ocorridas a partir do curso e as variáveis envolvidas para a intervenção junto a essa população no seu território de atuação.

Os dados quantitativos obtidos com a aplicação do questionário foram submetidos a uma análise estatística descritiva, e os dados qualitativos resultantes dos grupos focais tomaram as narrativas dos ACS como perspectiva avaliativa e complementar ${ }^{11}$, segundo os objetivos definidos para este trabalho.

O curso se insere como uma das ações propostas no projeto de pesquisa de intervenção 'Reorganização dos e nos processos de trabalho na Rede de Atenção Psicossocial mediada pela avaliação participativa', aprovado pelos Comitês de Ética da Faculdade de Ciências da Saúde da Universidade de Brasília (CEP/ FS-UnB), sob parecer de n. 2.200.022 e, também da Fundação de Ensino e Pesquisa em Ciências da Saúde - FEPECS/SES/DF, parecer de n. 2.270.086.

\section{Resultados e discussão}

\section{A organização e implementação do curso}

A intervenção prática orientou-se por uma abordagem pedagógica que busca a implicação dos ACS para refletirem sobre e analisarem a complexidade do uso, abuso e dependência de álcool e outras drogas e seus efeitos na saúde individual e coletiva, com vistas a uma mudança social possibilitada por reflexões teóricas sobre sua práxis.

O curso assumiu os pressupostos da abordagem problematizadora freiriana, ancorada na pedagogia social $^{12,13}$. Assim, o ACS foi convidado a olhar, analisar e compreender a sua realidade, identificar os fatores associados e desenvolver sínteses e proposições para a questão da problemática do uso de álcool e outras drogas, olhando a pessoa e o contexto, e não somente o sintoma, em um processo emancipatório. Buscamos, também, sintonizar a organização dos conteúdos e a mediação da aprendizagem com as diretrizes das políticas de redução de danos sociais e à saúde decorrentes do uso de álcool e outras drogas, descritas na Portaria GM 1.028. ${ }^{14}$

A proposta partiu do reconhecimento da inserção dos ACS nos territórios e pretendeu fomentar aprendizagens significativas mediadas pelo uso das tecnologias de informação e comunicação - recursos de educação a distância, na perspectiva de ampliar o protagonismo e a responsabilidade profissional. O resultado no processo formativo implicaria a formação de competências para intervenções mais efetivas nas situações de uso do álcool e outras drogas, nos processos socioculturais dos territórios, articulada com os recursos da rede social e da atenção psicossocial.

Considerando a finalidade da proposta do curso, a seleção e a organização dos conteúdos foram distribuídas em oito aulas: Aula 1 - Ambientação; Aula 2 - Território: espaço onde a vida acontece; Aula 3 - Acolhimento; Aula 4 - Legislação e políticas públicas como recurso protetivo para usuários de álcool e outras drogas; Aula 5 - Drogas: contextualização histórica, conceitos, classificação e efeitos no organismo; Aula 6 - Adolescentes, mulheres e idosos: o uso de álcool e outras drogas; Aula 7 - Família; e Aula 8 - Reflexões, desafios e perspectivas. Durante o referido processo, houve uma preocupação constante em associar os aspectos teóricos à realidade do cotidiano profissional do ACS. Para isso, adotaram-se recursos complementares, de leitura, vídeos, provocações para reflexão, exemplos, curiosidades e destaques de pontos fundamentais.

A autonomia do aluno, nesta proposta de curso a distância, constitui-se uma diretriz estruturante do processo de aprendizagem, pela qual se procurou respeitar e estimular a reflexão crítica, a potencialidade e autonomia de cada ACS, favorecendo uma participação ativa e responsável nas atividades propostas. 
Ao fazer referência à importância da reflexão crítica sobre a prática, Paulo Freire ${ }^{15}$ argumenta que "é pensando criticamente a prática de hoje ou de ontem que se pode melhorar a próxima prática”. E afirma ainda, “[...] quanto mais me assumo como estou sendo e percebo a ou as razões de ser, de por que estou sendo assim, mais me torno capaz de mudar, de promover-me, no caso, do estado de curiosidade ingênua para o de curiosidade epistemológica".

Dentre as estratégias utilizadas pela tutoria, destacam-se: mensagens com as orientações sobre as atividades da semana, postadas em diferentes espaços da plataforma; mensagens pessoais buscando estabelecer o acompanhamento do desenvolvimento individual dos cursistas; articulação com os cursistas assíduos para que motivassem os que não estavam participando; contato com os Caps-AD e/ou ESF de referência, buscando apoio para incentivo dos ACS; estímulo ao uso dos fóruns e compartilhamento de dúvidas e ideias; e, quando esgotados esses recursos, ligações por telefone para compreender a ausência e minimizar as dificuldades apontadas. Essas estratégias permitiram estabelecer relações mais próximas, favorecendo a adesão ao curso e o processo de aprendizagem.

Outros recursos também estiveram disponíveis ao longo do curso para favorecer a aprendizagem, quais sejam: Fórum de notícias, destinado a postagens semanais com um resumo do conteúdo a ser abordado nas aulas, orientações sobre as atividades a serem realizadas e demais informações relativas ao curso; Fórum de orientações e dúvidas, espaço aberto, destinado ao esclarecimento de dúvidas dos cursistas. Os ACS tiveram o período de dois meses e meio para acessarem os recursos supracitados.

Todo cursista poderia abrir um tópico de discussão, e as tutoras respondiam às questões e mediavam o debate. As respostas e mediações, antes de publicadas na plataforma, eram revisadas pela coordenadora de conteúdo; outra estratégia adotada foi o envio de mensagens pessoais a fim de propiciar um contato direto entre os atores envolvidos no curso: cursistas, tutoras e demais membros da equipe. Os assuntos abordados eram de natureza diversificada, a exemplo: orientação para realização das atividades, acompanhamento do desempenho individual de cada ACS, troca de informações, esclarecimento de dúvidas, entre outros.

O perfil dos participantes demonstrou que a maioria se declarou do sexo feminino (72,72\%), com faixa etária entre 30 e 49 anos (77,55\%), seguida da faixa entre 50 a 59 anos (13,63\%), e apenas 4,54\% estão entre 25 e 29 anos. Quanto à escolaridade, 47,72\% declarou possuir ensino superior completo, dois tinham pós-graduação, dois tinham superior incompleto e todos os demais tinham ensino médio completo. Quanto à naturalidade, a maioria nasceu no Distrito Federal e 93,2\% residem no território de atuação profissional.

Como resultado, tem-se que, dos 45 inscritos, 44 foram aprovados, o que representa 97,78\% dos inscritos. $\mathrm{O}$ alcance desse resultado deve-se principalmente à importância dada à tutoria, com orientação pedagógica que se estrutura em estratégias que focam a personalização da aprendizagem, estimulam a criticidade e convidam todos os atores a colaborarem na construção do conhecimento, por meio da problematização da realidade cotidiana e de um número de participantes que permite um acompanhamento individualizado. Ademais, foram estabelecidas diferentes estratégias de mobilização ao longo do curso, que também contou com o apoio dos Caps-AD e equipes da ESF. Ressalta-se que contar com a parceria dos Caps-AD aponta para o fortalecimento dos canais de diálogo entre saúde mental e atenção primária à saúde e ratifica a importância do trabalho conjunto.

\section{Avaliação do curso pelos ACS}

Na avaliação geral do curso, a totalidade dos cursistas respondentes do questionário afirmou que ele contribuiu para repensar a concepção sobre o uso e os usuários de álcool e outras drogas, 97,2\% julgaram que foram oferecidos subsídios para melhorar a intervenção junto a essa população e seus familiares, 80,6\% afirmaram que o mesmo correspondeu à realidade do trabalho e 47,2\% que o conteúdo do curso apresentou novidades, classificando-o como abrangente, diversificado e enriquecedor, além de ter atendido às expectativas dos cursistas. 


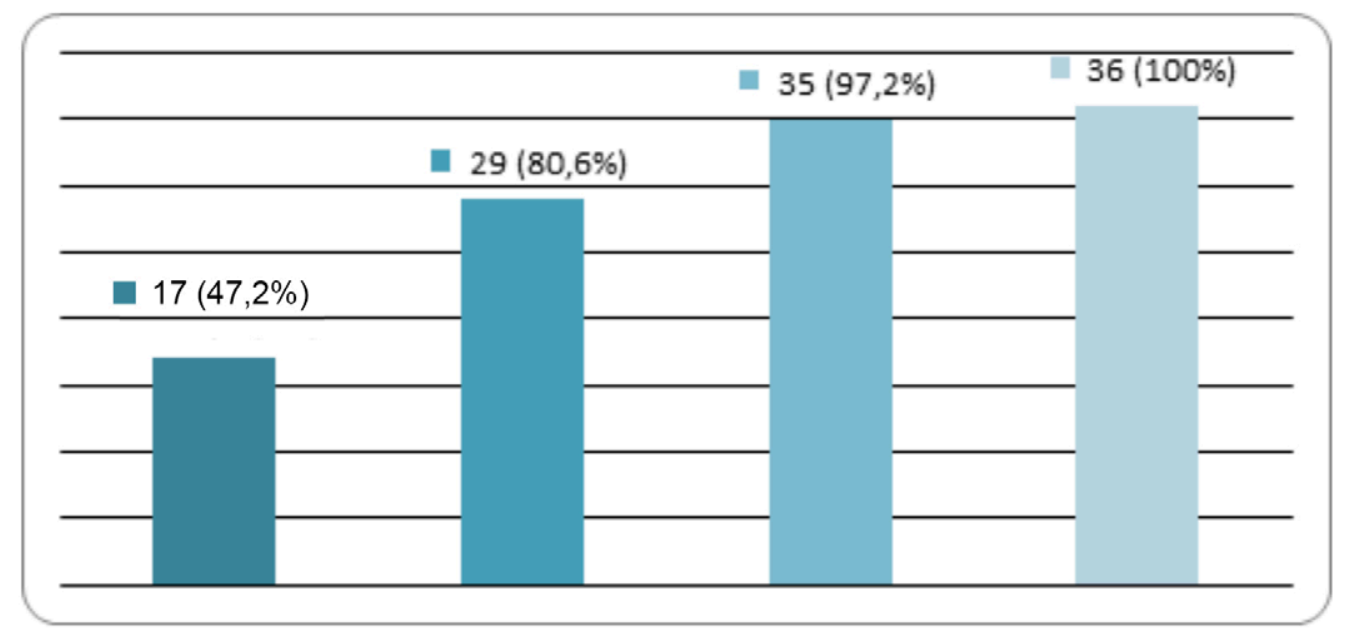

Figura 1 - Avaliação dos ACS sobre os fatores facilitadores na realização do curso. Brasília, 2017 Fonte: Os autores (2019).

Os ACS destacaram algumas contribuições desencadeadas pelo curso na prática profissional, cuja principal foi a ressignificação de suas próprias concepções a respeito do tema e, também, sobre quem é a pessoa do usuário que apresenta a problemática do uso de álcool e outras drogas e as demandas apresentadas no seu cotidiano de trabalho, estimulados pelos conteúdos acessados no curso que propõe o uso de uma abordagem mais acolhedora, compreensiva e ampliada acerca da complexidade envolvida no cuidado do usuário de álcool e outras drogas.

Processos de educação permanente em serviço, seja em modalidade EAD ou presencial, híbrida ou mista, podem ressignificar opiniões, preconceitos e as experiências dos próprios profissionais, rompendo com práticas distanciadas e estigmatizantes para melhor atender as necessidades dos usuários. "As constantes mudanças que vêm ocorrendo no setor saúdem mostram a necessidade do desenvolvimento dos profissionais, para a garantia da qualidade da assistência prestada à população. O mundo do trabalho exige cada vez mais dos profissionais o desenvolvimento de uma postura crítico-reflexivo, e, para isso, é necessária a aquisição de conhecimentos e competências técnicas e relacionais, de forma a promover o desenvolvimento profissional e pessoal dos sujeitos"16.

Essa mudança é muito significativa diante de uma sociedade que reduz os usuários de substâncias psicoativas a uma condição - 'drogado', 'bêbado', 'fraco', 'sem força de vontade', deixando de reconhecer as demais dimensões dessa pessoa, suas potencialidades e competências, reforçando, assim, uma visão moralista. Quando profissionais de saúde são orientados por essa visão, podem ser encontradas práticas discriminatórias, estigmatizantes, excludentes e/ou negligentes, por não reconhecerem o uso de drogas como um problema de saúde, o que representa uma fragilidade do serviço de saúde. Portanto, a mudança de concepção por parte dos ACS significa a possibilidade de garantia de direitos humanos e sociais, com efetiva atenção às necessidades de saúde do cidadão usuário de substâncias psicoativas.

Outro fator que contribuiu para o sucesso do curso foi a linguagem empregada, acessível e contextualizada, pois $97,2 \%$ dos respondentes do questionário afirmaram que a linguagem adotada foi de fácil compreensão. Houve uma preocupação constante da equipe em associar os aspectos teóricos à realidade do cotidiano profissional do ACS. Para isso, adotaram-se recursos complementares de leitura e vídeos, embora a maioria dos cursistas tenha afirmado não haver utilizado a biblioteca virtual, além de provocações para reflexão, exemplos, curiosidades e destaques de pontos fundamentais nos textos das aulas.

Na EAD, um aspecto importante é a apresentação do ambiente virtual de aprendizagem, neste caso, a plataforma Moodle. É necessário que ela seja de fácil utilização, com recursos que facilitem a aprendizagem e não seja uma barreira ao processo. Quanto a esse aspecto, os cursistas destacaram que ela foi bem 
organizada, bem estruturada, acessível e funcional, mesmo para os que utilizavam essa ferramenta pela primeira vez, evidenciando a importância da aula introdutória de ambientação à plataforma e seus recursos.

Considerando o destaque que os ACS deram ao recurso da tutoria na motivação e adesão ao curso, ele será abordado em separado, a seguir, pois traz elementos de reflexão nas propostas de educação permanente em saúde.

\section{A tutoria: um diferencial no curso EAD}

A avaliação dos cursistas apoia a afirmativa de que a proposta de tutoria realizada foi um diferencial para alcançar esses resultados.

Quando questionados sobre os fatores que contribuíram para que os cursistas se organizassem melhor durante a realização do curso, a maioria $(86,1 \%)$ apontou as mensagens enviadas pelas tutoras, seguidas de outros recursos da plataforma, como as informações contidas na pasta 'Sobre o curso', quais sejam: cronograma, programa e boas-vindas. Em terceiro lugar, destacaram as informações passadas pessoalmente por outros cursistas. Essa foi uma das estratégias adotadas pela tutoria: articular com o participante assíduo da mesma ESF que mantivesse contato com os que estavam ausentes, inclusive para saber se estavam com dificuldades ou de que forma a tutoria poderia contribuir no processo de aprendizagem. Por último, apontaram, tanto no Fórum de Notícias como no Fórum de Orientações e Dúvidas, que conseguiram partilhar as reflexões com outros profissionais, mesmo com os que não fizeram o curso, o que pode indicar que a temática extrapolou o âmbito dos ACS cursistas.

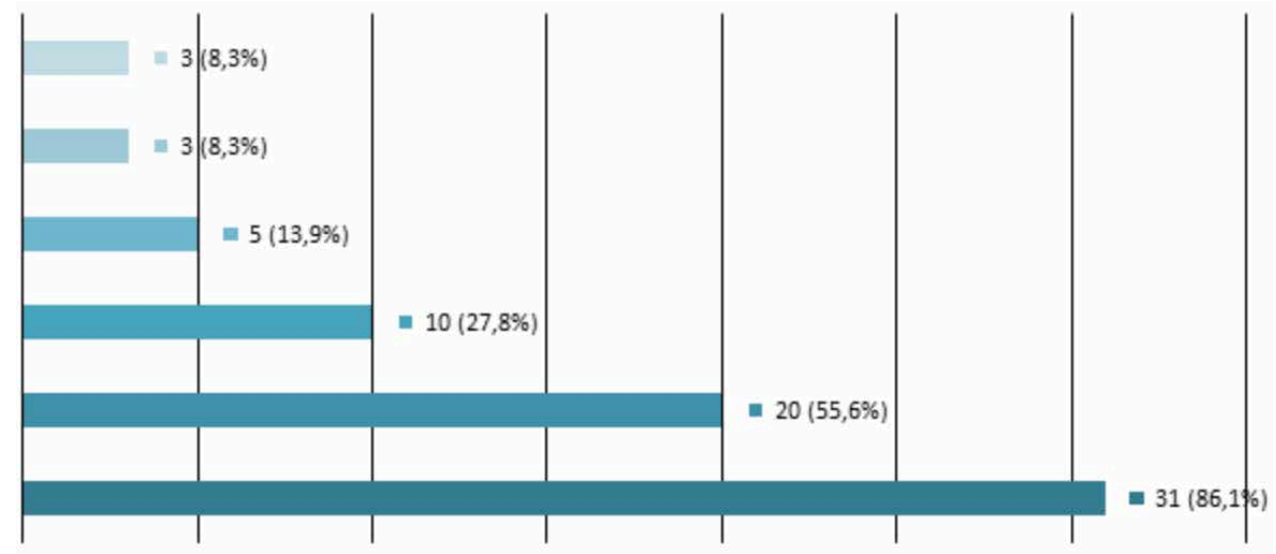

Figura 2 - Fatores favoráveis, segundo avaliação dos ACS, para a realização do curso. Brasília, 2017. Fonte: Os autores (2019).

Em relação à tutoria, os cursistas avaliaram positivamente o seu apoio, com destaque para a competência técnica, a organização e a comunicação desenvolvida em ambiente virtual. A totalidade dos respondentes considerou o papel da tutoria como excelente, ressaltando que foi um diferencial para a motivação e adesão ao curso. Enfatizaram o compromisso da tutoria com o curso e os alunos, as competências técnicas e a disponibilidade para prestar esclarecimentos de dúvidas quanto aos conteúdos e ao processo didáticopedagógico de forma célere.

Para ilustrar, foram extraídas do questionário de avaliação expressões como 'sempre mantendo contato com cursistas e sanando dúvidas', 'preocupada com o desenvolvimento do aluno no curso e bastante atenciosa' e 'superdedicada com os alunos para que todos tivessem a oportunidade de se enriquecerem com novos conhecimentos e com certeza se colocarem como profissionais mais atuantes dentro do seu território'.

Percebe-se que promover processo de interação e expressão entre tutores e cursistas no Moodle traz evidência para: atenção, dedicação, presença na plataforma e fora dela, com mensagens e telefonemas para motivação e adesão, o que indica que a atuação da tutoria é recurso diferencial em curso EAD. 
No que se refere ao papel da tutoria, cabe dizer que, mesmo com a autonomia e a flexibilidade para realização das atividades que são conferidas aos alunos de um curso realizado a distância, a figura do tutor ganha destaque. Ele é um tipo de educador que indica caminhos novos e propicia a interação entre os conteúdos e os cursistas, contribuindo para que eles repensem seus conceitos, de modo que esse processo de construção pode ser tão importante quanto o do ensino presencial ${ }^{17}$.

O tutor tem diversas atribuições atreladas às três dimensões, técnica, gerencial e pedagógica ${ }^{18}$. Nessa acepção, a técnica se refere ao domínio dos recursos tecnológicos que são disponibilizados no curso; a gerencial está relacionada à capacidade de planejar ações em curto e médio prazo, bem como, elaborar estratégias; e a pedagógica indica que o tutor, além de ter domínio do conteúdo específico a ser trabalhado, deve estimular os alunos a buscar respostas, estar aberto a aprender e a elaborar estratégias motivacionais ao longo do processo de aprendizagem ${ }^{18}$.

Considerando essas três dimensões, percebe-se que a presença de uma tutoria comprometida com a capacitação constitui-se um diferencial para a educação a distância, favorecendo ainda mais as partilhas de saberes e os processos de aprendizagem.

\section{Percepções dos ACS sobre a experiência de capacitação EAD sobre abordagem preventiva na Atenção Básica ao uso de drogas}

Os achados do questionário de avaliação foram reforçados pelas análises feitas pelos cursistas nos grupos focais realizados em Samambaia e Sobradinho. Foi evidenciado também que princípios e conceitos básicos do trabalho com usuários de substâncias psicoativas e familiares, trabalhados ao longo do curso, foram destacados na fala dos ACS.

Em ambos os grupos, os ACS destacaram a importância do curso para a reflexão de suas concepções e posturas acerca do usuário de substâncias psicoativas e suas famílias.

O meu preconceito, conceito preconcebido ... é olhar pra pessoa e ver ela de outra forma, é tentar não mais marginalizar. O que já mudou é a questão do preconceito. Eu já tenho uma forma diferente de olhar pra pessoa (GF Samambaia).

O que o curso trouxe de diferente foi que a gente tá vendo muito a pessoa em si, só ela, ela ali com aquele problema que ela tem. E o que o curso trouxe foi justamente a gente entender o contexto em que essa pessoa tá inserida (GF Samambaia).

Verifica-se que a modalidade EAD pode favorecer, no processo formativo, a aquisição de conhecimentos, como também de habilidades sensíveis, em que a dimensão afetiva pode facilitar a expressão de subjetividades e as mudanças de paradigmas.

Os ACS também afirmaram que o curso forneceu subsídios para melhorar a intervenção, especialmente quanto ao acolhimento e à segurança para abordarem os casos.

É a questão da confiança, quando a gente passa essa confiança, eles confiam mais, acho que antes tava faltando um pouco isso (GF Sobradinho).

Nesse curso a gente vê muito que a gente tem que olhar a pessoa sem criticar as ações dela, tem que ter o ouvido pra escutar sem criticar, sem julgar. Simplesmente acolher, conversar e tentar entender (GF Samambaia).

Os textos são muito ricos, então, na verdade vocês forneceram pra gente ferramentas, $e$ isso modifica o nosso olhar (GF Samambaia).

Ressaltaram que o curso contribuiu para sensibilizar sobre a identificação e acompanhamento de casos de uso prejudicial de álcool e outras drogas e para fortalecer a intencionalidade de determinadas perguntas em questionários já empregados pelos ACS na abordagem de indivíduos e famílias. 
Era como se acontecesse assim: a gente perguntava, seguindo nossa ficha, "tem alguém em casa que faz uso de álcool?”. Aí respondem: “ah, esporadicamente, ah, eventualmente”. Então a gente já recebia essa resposta como se a gente já soubesse dela. Hoje não, a gente já questiona mais, chega a atrapalhar: "você já chegou atrasado no trabalho por causa do ontem, do feriado, do fim de semana que você bebeu?”(GF Sobradinho).

No início do programa, a gente ia fazer a visita, se soubesse que tinha um usuário, a gente nem passava naquela casa, com medo e tal, e aí essa visão começou a mudar, $e$ realmente vem mudando, e esse curso trouxe algo mais pra gente (GF Samambaia).

E o curso também veio pra dar aquela alavancada na gente, falar assim: "Poxa, você não pode ser assim. Você tem que ser diferente." O dia a dia nosso aqui é corrido, você vê aqui como a unidade é um corre-corre danado, só que a gente tem que ter aquele ponto, dar uma respirada, e vamos de novo (GF Samambaia).

Estudo brasileiro realizado com enfermeiras pediatras indica que experiências em EAD são estratégias importantes para educação permanente em serviço, de maneira a ampliar o acesso e favorecer a organização do tempo do profissional trabalhador, e, ainda, dispor de ensino aprendizado de qualidade, seja em processos educacionais complementares ou formais em currículos de cursos, mas que também cabe refletir que podem ser "entendidos como movimentos políticos que promovam a educação para o Sistema Único de Saúde"16.

Os ACS abordaram questões que são estruturantes para a constituição de uma rede assistencial e de proteção aos usuários, destacando a mudança na compreensão da responsabilidade que a atenção básica deve ter sobre os usuários da saúde mental e a necessidade de fortalecimento da rede de atenção a RAS.

A gente tem acesso à casa, à mãe, ao irmão, a alguém que fala, é a porta de entrada mesmo, que é através daí que a atenção secundária pode agir (GF Sobradinho).

O curso deu um up pra gente, porque depois que eu comecei a fazer, hoje eu já tenho uma parceria com o Caps, onde eu tenho a liberdade dentro do Caps de discutir casos. Tem dois pacientes que eu discuto direto, a psiquiatra já esteve lá fazendo visita com a gente (GF Sobradinho).

Acho que a gente já falou de facilidade, só que tem também a parte da dificuldade. Da questão do matriciamento, da gente entender que entrariam as redes de atenção à saúde. Mas aí o que tava faltando seria a parceria, que a gente falou também, com o Caps-AD. $E$ o que mais a gente tem dentro da rede que poderia ser ofertado para esses pacientes? (GF Samambaia).

O estudo realizado por Costa et al. ${ }^{19}$ alerta sobre a importância de constituir uma rede assistencial sobre drogas, tanto no âmbito da saúde, com destaque ao lugar do Caps-AD como ordenador da rede e dos hospitais, como no âmbito da assistência social, e a pluralidade de dispositivos, como na sociedade civil, a exemplo dos grupos de ajuda mútua, dada a complexidade envolvendo o uso de substâncias psicoativas. Aponta limites e desafios, como a insuficiência da RAS e a necessidade de melhores condições de trabalho e de investimento como uma política pública para melhor enfrentamento dos problemas e organização dessa rede assistencial.

Às vezes, o que acontece é um descompasso. O trabalho tem que estar interligado. Um exemplo bem prático: morador de rua que eu abordei, que é usuário de álcool,... você tenta na rede de que maneira você pode acolher essa pessoa. Você chega até uma assistente social, aí você se depara com um problema de que ela tem problemas pessoais, e depois ela tem problema de falta de carro e depois ela não te dá um feedback e simplesmente a pessoa continua na mesma condição que se encontrava quando eu tentei falar com ela em janeiro. Então... são essas coisas, esse descompasso... (GF Samambaia).

Realizar articulação com serviços e equipamentos existentes nos territórios é um desafio que está posto e se torna cada vez mais necessário. Os profissionais e serviços, ao trabalharem isoladamente, correm o risco de reforçar abordagens com ênfase hospitalocêntrica, segrecionista e proibicionista. Abandonar a perspectiva de trabalhar de forma isolada é um imperativo que corrobora a desinstitucionalização dos usuários e contribui para o fortalecimento da reforma psiquiátrica. São muitos os desafios para se 
estruturar, mas cabe pensar as estratégias que estão sob a governabilidade do profissional/equipe de saúde para melhorar a atenção à saúde dos usuários.

Na nossa equipe, a gente tá tentando trabalhar junto à equipe toda pra montar reuniões aqui mesmo na clínica, roda de conversa com familiar, amigos e o próprio usuário. Já era pra acontecer agora em novembro, mas tivemos várias questões, que igual você falou, que impedem... então, nós estamos trabalhando para formar rede. A gente fechou algumas reuniões para montar parcerias, fizemos reuniões e até veio o Caps, veio igreja, comunidade, Creas, associação. E o próximo passo será essa roda de conversa que nós iremos convidar o usuário, o familiar (GF Sobradinho).

O trabalho em conjunto com os demais equipamentos da rede de atendimento contribui para a autonomia dos sujeitos e para reforçar a lógica de que os usuários de substâncias psicoativas não são unicamente integrantes de uma rede específica. Eles são do SUS e do Sistema Único da Assistência Social (Suas) também. Eles são de todo o território, dos espaços que já ocupam e dos que almejam ocupar, pertencer. Fortalecer a Raps é fundamental, e esee curso teve um olhar cuidadoso para a relevância do fortalecimento da abordagem psicossocial, ao contemplar os ACS nessa formação para essa temática de grave dimensão para a saúde pública. Esse primeiro momento precisa ser estendido para qualificar as equipes profissionais da Atenção Básica para maior capilaridade das ações de promoção e de prevenção que possam trazer mudanças para a saúde das pessoas.

\section{Conclusões}

O resultado exitoso obtido no curso para ações preventivas em situações de uso de substância psicoativas, na modalidade $\mathrm{EAD}$, teve como fatores envolvidos, segundo a avaliação dos ACS, a organização e qualidade dos conteúdos que contemplaram o contexto das realidades e da necessidade de formação profissional para o trabalho na atenção básica e o papel da tutoria, ao fazerem a estimulação contínua para o envolvimento e participação ativa dos ACS no decorrer do curso. Esses fatores favoreceram a ressignificação tanto de conceitos como de práticas por parte dos ACS, potencializando a capacidade de atuação nos territórios junto aos usuários de substâncias psicoativas e seus familiares, orientados pela abordagem psicossocial e da redução de danos.

Com uma adesão de quase $100 \%$ na experiência relatada, constatou-se que a proposta de integrar a tutoria em cursos EAD autoinstrucional foi um diferencial para a não evasão, considerando dados da literatura em oferta EAD. A proposta do curso, com incremento do recurso da tutoria no trabalho formativo dos ACS, propiciou relações sociais significativas que favoreceram o aprofundamento dos conteúdos, esclarecimentos de dúvidas e, fundamentalmente, a adesão e aproveitamento dos ACS diante dos objetivos propostos para a formação desse profissional de saúde nesse curso. A relação estabelecida entre a tutoria e os ACS nesses espaços sociais do curso facilitou a problematização de vivências cotidianas dos ACS nas situações de uso de drogas no território, com a produção de novos sentidos para um cuidar mais subjetivo e ético.

Cabe ressaltar a importância do apoio das equipes dos Caps-AD e ESF de Ceilândia, Santa Maria, Samambaia e de Sobradinho, que reconhecem a complexidade e a dificuldade de uma melhor intervenção profissional na atenção das pessoas com necessidades de saúde devido ao uso de álcool e outras drogas e compartilharam a responsabilidade desse trabalho com a universidade. Essa articulação em rede e intersetorial é importante para ampliar os processos de formação dos profissionais de saúde e para intervenções ampliadas e integrais para o enfrentamento dos problemas de saúde.

Por fim, esse curso significou a confirmação que processos de educação permanente em serviços podem ser otimizados pela oferta de curso de educação a distância, quando da responsabilidade social e ética em contribuir para a melhoria do cuidado com as pessoas com necessidades de saúde em decorrência do uso, abuso e dependência de álcool e outras drogas na perspectiva do modelo de atenção psicossocial; 
o reconhecimento da importância de contribuir no planejamento e execução de ações de formação, aperfeiçoamento de práticas no campo da saúde mental e fortalecimento da Raps DF; e o compromisso em divulgar experiências inovadoras, práticas emancipatórias e articuladas à rede social.

\section{Referências}

1. Peduzzi M, Guerra DAD, Braga CP, Lucena FS, Silva JAM. Atividades educativas de trabalhadores na atenção primária: concepções de educação permanente e de educação continuada em saúde presentes no cotidiano de Unidades Básicas de Saúde em São Paulo. Interface (Botucatu) [Internet]. 2009 jul./set. [citado em 2018 ago. 02];13(30):121-34. doi: http://dx.doi.org/10.1590/S1414-32832009000300011

2. Presidência da República (BR). Casa Civil. Subchefia de Assuntos Jurídicos. Lei n. 9394 de 20 de dezembro de 1996. Estabelece as diretrizes e bases da educação nacional [Internet]. DOU [Internet]. 1996 [citado em 2018 ago. 07]. Disponível em: https://bit.ly/1OgopZ0

3. Oliveira MAN. Educação a Distância como estratégia para a educação permanente em saúde: possibilidades e desafios. R Bras Enferm [Internet]. 2007 [citado em 2018 ago. 02];60(5):585-89. doi: http://dx.doi.org/10.1590/S0034-71672007000500019

4. Ortiz MCL, Ribeiro RP, Garanhani ML. Educação a Distância: uma ferramenta para educação permanente de enfermeiros que trabalham com assistência perioperatória. Cogitare Enferm [Internet]. 2008 [citado em 2018 ago. 2];12(4):558-65. Disponível em: https://bit.ly/2J5AU2D

5. Cury L, Sousa PC, Kudeken SS. Proposta de curso na modalidade EAD: introdução à pesquisa científica a partir da disciplina teoria e método de pesquisa em comunicação da ECA/USP. In: Anais do $23^{\circ}$ Congresso Internacional ABED de educação a distância; 2017 set. 17-21; Foz do Iguaçu, PR. Foz do Iguaçu: ABED; 2017. Disponível em: https://bit.ly/2HuQ279

6. Alves VS. Um Modelo de Educação em Saúde para o Programa Saúde da Família: pela integralidade da atenção e reorientação do modelo assistencial. Interface (Botucatu) [Internet]. 2005 set./fev. [citado em 2018 ago. 02];9(16):39-52. doi: https://bit.ly/2ES9VSL

7. Castanha AR, Araújo LF. Álcool e agentes comunitários de Saúde: um estudo das representações sociais. Psico-USF [Internet]. 2006 [citado em 2018 ago. 2];11(1):85-94. doi: http://dx.doi.org/10.1590/S1413$\underline{82712006000100010}$

8. Ministério da Saúde (BR). Portaria no 3.088 de 23 de dezembro de 2011. Institui a Rede de Atenção Psicossocial para pessoas com sofrimento ou transtorno mental e com necessidades decorrentes do uso de crack, álcool e outras drogas, no âmbito do Sistema Único de Saúde (SUS). DOU [Internet]. 2011 [citado em 2018 ago. 07]. Disponível em: https://bit.ly/29zD847

9. Matta ANB, Locatelli D, Silva EA, Contreras, MV, Bittencourt, BA, Noto AR. Processos formativos em álcool e outras drogas para trabalhadores da rede pública do município de São Paulo: a experiência do CRR-DIMESAD-UNIFESP. Pesq Prát Psicossoc [Internet]. 2016 dez. [citado em 2018 ago. 03];11(3):63749. Disponível em: https://bit.ly/2SVdxs5

10. Mendonça AVM, Sousa MF, Linhares RN, Cabral, JC, Paixão, PBS. Inclusão digital dos agentes comunitários de saúde no Brasil: novas formas de aprender em rede. Tempus Actas Saúde Col [Internet]. 2009 [citado em 2018 ago. 02];3(1):28-37. Disponível em: https://bit.ly/2TOjufb

11. Trad LAB. Grupos focais: conceitos, procedimentos e reflexões baseadas em experiências com o uso da técnica em pesquisas de saúde. Physis [Internet]. 2009 [citado em 2018 ago. 03];19 (3):777-96. doi: http://dx.doi.org/10.1590/S0103-73312009000300013

12. Paula EMAT, Santos K. A teoria de Paulo Freire como fundamento da pedagogia social. Interfaces Cient [Internet]. 2014 [citado em 2019 fev. 11];3(1):33-44. doi: http://dx.doi.org/10.17564/2316$\underline{3828.2014 v 3 n 1 p 33-44}$

13. Asineli-Luz A. Pedagogia social e prevenção do abuso de drogas. In: Anais do $2^{\circ}$ Seminário Internacional de Representações Sociais, Subjetividade e Educação; 40 Seminário Internacional sobre profissionalização docente; $11^{\circ}$ Congresso Nacional de Educação [Internet]. 2013 set. 23-26; Curitiba, PR. Paraná: EDUCERE; [citado em 2019 fev. 11]; Disponível em: http://educere.bruc.com.br/arquivo/ pdf2013/7616 7016.pdf 
14. Ministério da Saúde (BR). Portaria 1.028 GM de $1^{0}$ de julho de 2005. Determina que as ações que visam à redução de danos sociais e à saúde, decorrentes do uso de produtos, substâncias ou drogas que causem dependência, sejam reguladas por esta Portaria. [DOU] [Internet]. 2005 [citado em 2019 fev. 11]. Disponível em https://bit.ly/2N4oepX

15. Freire P. Pedagogia da autonomia: saberes necessários à prática educativa. São Paulo: Paz e Terra; 1996.

16. Silva AN, Santos AMG, Cortez EA, Cordeiro BC. Limites e possibilidades do ensino à distância (EaD) na educação permanente em saúde: revisão integrativa. Ci Saúde Coletiva [Internet]. 2015 [citado em 2018 ago. 30];20(4):1099-1107. doi: http://dx.doi.org/10.1590/1413-81232015204.17832013

17. Schlosser RL. A atuação dos tutores nos cursos de educação a distância. Colabor@. 2010 [citado em: 2018 ago. 3];6(22):1-11. Disponível em: https://bit.ly/1U4XyUO

18. Bernardino HS. A tutoria na EAD: os papéis, as competências e a relevância do tutor. Paidei@. 2011 [citado em 2018 ago. 3];2(4):1-7. Disponível em: https://bit.ly/2WOriYH

19. Costa PHA, Mota DCB, Paiva FS, Ronzani TM. Desatando a trama das redes assistenciais sobre drogas: uma revisão narrativa da literatura. Ci Saúde Coletiva [Internet]. 2013 [citado em 2018 ago. 2];20(2):395-406. doi: http://doi.org/10.1590/1413-81232015202.20682013 